\title{
PERFIL DE UTILIZAÇÃO DE REPOSITORES PROTÉICOS NAS ACADEMIAS DE BELÉM, PARÁ ${ }^{1}$
}

\section{PATTERN OF UTILIZATION OF PROTEIN SUPPLEMENTS IN ACADEMIES IN BELÉM, PARÁ}

\author{
Ana Cláudia Matos de ARAÚJO² \\ Yone de Nazareth Gonçalves SOARES ${ }^{2}$
}

RESUMO

\begin{abstract}
Este estudo foi realizado no primeiro semestre de 1996 e teve como alvo os freqüentadores das academias da cidade de Belém (PA). Além de pesquisa bibliográfica referente ao metabolismo energético e protéico, necessidades nutricionais de desportistas e suplementação com proteínas e aminoácidos, foi realizada uma pesquisa de campo com o objetivo de traçar o perfil de utilização de suplementos nutricionais, com ênfase em produtos a base de proteínas e aminoácidos, por sexo, idade e tempo de prática de atividade física. A pesquisa de campo envolveu uma amostra de 18 academias e 388 entrevistados, dos quais 103 (27\%) faziam uso de algum tipo de suplemento, sendo que 45 destes (44\%) utilizavam repositores protéicos. Das justificativas para opção de uso desses suplementos, destacou-se a "indicação profissional" que comparada ao quadro técnico existente nessas unidades, em que apenas 4 das 18 academias pesquisadas apresentavam nutricionistas ou médicos, indica que a utilização desses produtos por parte dos praticantes de atividades físicas está sendo indevida.
\end{abstract}

Termos de indexação: nutrição, esportes, suplementação alimentar.

\begin{abstract}
The presente study was carried out in the first semester of 1996, aiming to evaluate users of academies in Belém, Pará, Brazil. Beyond vast bibliographic research about the energetic and proteic metabolism, sportsmen's nutritional necessities and supplementation with protein and amino acids, a field research was carried out with the purpose of tracing the profile of utilization of nutritional suplements with emphasis on protein and amino acid products, considering sex, age and period of physical activity practice. The research involved a sample of 18 academies and 388 interviewees; 103 of then (27\%) used some kind of supplementation and 45 of these (44\%) used protein supplements. Among the
\end{abstract}

\footnotetext{
(1) Artigo baseado na monografia, Perfil de utilização de suplementos com proteínas e aminoáciodos nas Academias de Belém-Pará. Belém: UFPA, 1996.67p.

(2) Acadêmicas do Curso de Graduação em Nutrição, Universidade Federal do Pará, Av Augusto Correa, 1, Campus Universitário, 66075-110, Belém, PA.
} 
justifications given for the option of using the supplementation, the "professional indication" stood out from the others. Comparison with technical list existing in these units, in which only 4 of the 18 academies included in the sample had nutritionists or doctors, suggests that the utilization of these products by physical activities practitioners may be inadequate.

Index terms: nutrition, sports, supplementary feeding.

\section{INTRODUÇÃO}

Os indivíduos cada vez mais têm procurado adquirir como hábito a prática de atividades regulares, quer seja por motivos estéticos ou para a manutenção de um estilo de vida saudável, sem contudo tomar parte em competições, caracterizando assim o conceito de esportista (Rodrigues, 1984).

Há uma importante relação entre a nutrição e a atividade física, porque a capacidade de rendimento do organismo melhora através de uma nutrição adequada, com a ingestão equilibrada de todos os nutrientes, sejam eles carboidratos, gorduras, proteínas, minerais e vitaminas.

Os requerimentos nutricionais de indivíduos fisicamente ativos diferem apenas quantitativamente em relação aos de indivíduos sedentários por necessitarem de uma maior ingestão energética de origem alimentar. Esta energia é empregada na produção de Adenosina Trifosfato (ATP), que representa a fonte imediata de energia a ser utilizada pela célula na realização de seu trabalho biológico (Fox et al, 1991; Organización..., 1991; Bowers \& Fox, 1995).

A produção energética constitui uma atividade permanente que requer processos tanto aeróbicos (sistema do oxigênio) quanto anaeróbicos (sistema ATP-PC e glicólise anaeróbica) (Fox et al., 1991).

Os exercícios são divididos em duas categorias: de curta duraçãoe altaintensidade (noqual predominam os sistemas anaeróbicos para a produção energética) e de longa duração e baixa intensidade (no qual o sistema aeróbico é o principal operante). No repouso também o sistema predominante para a produção de energia é o aeróbico (Katch \& Mcardle, 1984; Fox et al., 1991; Bowers \& Fox, 1995).

As proteínas geralmente não são utilizadas como substratos energéticos significativos na maior parte das formas de exercício, contribuindo com apenas 5 a $10 \%$ das necessidades energéticas em algumas circunstâncias, porém respondem pelo suprimento adequado de aminoácidos essenciais que garantem o crescimento, desenvolvimento e reconstituição tecidual como a musculatura esquelética de indivíduos praticantes de atividades físicas regulare (Fox et al., 1991; Bowers \& Fox, 1995).

Objetivando melhorar o rendimento físico, os esportistas vêm tornando-se cada vez mais adeptos ao uso de suplementos nutricionais, o que abre espaço para a utilização indevida dos mesmos, podendo traduzir-se em riscos para a saúde, tais como:

a) Desequilíbrio: Situação em que uma mudança nas proporções dos aminoácidos de uma dieta é traduzida em redução no crescimento de animais experimentais.

b) Antagonismo: Quando a ingestão em excesso de um determinado aminoácido reduz a utilização de outro aminoácido estruturalmente semelhante. Como exemplo, o excesso de leucina reduz a utilização de isoleucina e valina, e os efeitos adversos só se corrigem quando se administra os aminoácidos antagônicos. Outro exemplo é o da lisina, cujo excesso na ração de animais de experimentação aumenta as necessidades de arginina.

c) Toxidez: Ocorre em situações em que há a ingestão excessiva de aminoácidos individuais. $\mathrm{O}$ caso mais crítico é o da metionina que em concentrações, na dieta apenas, três vezes superiores as necessidades do organismo, provoca redução no crescimento; para os outros aminoácidos a dose limite é superior a dez vezes.

Essa premissa se reforça quando se analisa o posicionamento de Kacth e Mcardle, e Krause e Mahan, que afirmaram não existir nenhum benefício em ingerir proteínas em excesso, uma vez que as energias extras em forma de proteínas transformam-se em gorduras e são armazenadas em depósitos subcutâneos. O excesso de proteína pode ser prejudicial, pois sobrecarrega o fígado, órgão responsável pela metabolização de aminoácidos, e os rins, já que grande 
quantidade de subprodutos do metabolismo protéico como uréia, amônia e outros produtos nitrogenados são eliminados por via urinária (Kacth \& Mcardle, 1984; Krause \& Mahan, 1991; Newsholme et al., 1992).

A utilização de suplementos com proteínas e aminoácidos comerciais tem aumentado entre os atletas e esportistas, tendo como objetivo a substituição de proteínas da dieta, o uso para aumentar o valor biológico das proteínas da refeição e ainda por seus efeitos anticatabolizantes e efeitos anabolizantes (Kreider et al.,1993; Werustky, 1993; Fernandes \& Vieira, 1994).

Estudos realizados na população norteamericana e australiana mostram que a utilização de suplementos nutricionais é comum entre os adeptos da musculação e do levantamento de peso (Burke \& Read, 1993; Cardoso, 1994). Sob esse ponto de vista e com base na comercialização livre desses produtos, surge o interesse em estudar o grupo de esportistas freqüentadores das academias de Belém (PA), com o objetivo de verificar o perfil de utilização de repositores proteínicos.

\section{MATERIAL E MÉTODOS}

Por estar incluído na área da nutrição esportiva, este trabalho exigiu requisitos importantes que foram monitorados por profissionais da área e estão descritos abaixo.

O trabalho consta de um estudo transversal e tem como principais referências as academias da cidade de Belém (PA). A identificação das mesmas foi possível através de um levantamento realizado na Junta Comercial do Estado do Pará (JUCEPA), que forneceu uma listagem contendo além do registro das 143 academias, o nome do proprietário e o endereço, não informando, porém, a situação da academia quanto ao seu funcionamento, o que foi feito através de confirmação telefônica.

Oresultado da primeira etapa foi a identificação de 55 academias registradas e em atividade, distribuídas pelos bairros da cidade. Como essa distribuição apresentou frequiências variáveis, fez-se uma listagem por ordem decrescente do número de academias de cada bairro. A partir daí foram estabelecidas 9 alternativas para definição do tamanho amostral, optando-se por uma amostra intermediária de 18 academias, que reflete um nível de confiança 2 e erro máximo permitido 4.

A escolha das unidades foi feita a partir do processo de amostragem probabilística casual simples sem reposição, ou seja, através de sorteio que garantiu a todas as unidades, probabilidades idênticas de participarem da amostra.

De posse dos nomes e endereços das 18 academias, realizou-se a pesquisa de campo que teve como objetivos, o conhecimento do perfil de utilização de repositores protéicos, seus respectivos nomes comerciais, identificando o uso por sexo, idade e atividade física. A pesquisa foi dividida em duas partes.

A primeira compreendeu visita a todas as unidades componentes da amostra para identificação do número total de alunos, por sexo e atividade física desenvolvida. O instrumento utilizado para a coleta de dados foi a ficha de identificação da academia (Anexo 1).

$\mathrm{Na}$ segunda parte, que constou da aplicação direta do formulário (Anexo 2), também optou-se pelo estudo amostral, dada a grandeza do número (5 050 usuários) e o curto espaço de tempo disponível para realização do trabalho, obtendo-se novamente 9 opções, das quais foi escolhida a de 388 usuários, divididos proporcionalmente por sexo, através de amostra casual estratificada.

A tabulação dos dados coletados foi feita manualmente e os resultados seqüencialmente apresentados em 7 tabelas. A listagem contendo o nome comercial de todos os produtos a base de proteínas e aminoácidos e frequiência de uso citados pelos entrevistados nas academias de Belém, encontra-se no Anexo 3.

\section{RESULTADOS E DISCUSSÃO}

Os dados globais da Tabela 1 indicam um nível de utilização de suplementos nutricionais na faixa de $27 \%$, entretanto a análise desse perfil se modifica quando se faz uma estratificação por sexo, pois nesse caso o grupo de homens alcança $42 \%$ de utilização contra $23 \%$ do grupo de mulheres. 
Tabela 1. Utilização de suplementos nutricionais, segundo o sexo. Academias de Belém (PA), 1996.

\begin{tabular}{|c|c|c|c|c|c|c|c|}
\hline & \multirow[t]{2}{*}{ Sexo } & \multicolumn{2}{|c|}{ Masculino } & \multicolumn{2}{|c|}{ Feminino } & \multicolumn{2}{|c|}{ Total } \\
\hline Utilização de suplementos & & $\mathrm{n}$. & $\%$ & $\mathrm{n}$. & $\%$ & $\mathrm{n}$. & $\%$ \\
\hline Sim & & 33 & 42 & 70 & 23 & 103 & 27 \\
\hline Não & & 46 & 58 & 239 & 77 & 285 & 73 \\
\hline Total & & 79 & 100 & 309 & 100 & 388 & 100 \\
\hline
\end{tabular}

Aqueles que relataram utilizar algum tipo de suplemento nutricional, $43 \%$ referiram-se a suplementos a base de proteínas e aminoácidos.

Observou-se que a utilização de suplementos prevaleceu nos homens na faixa etária compreendida entre 19 e 27 anos (61\%), e nas mulheres na faixa etária de 27 a 35 anos (31\%) (Tabela 2).

Tabela 2. Utilização de suplementos protéicos, segundo sexo e faixa etária. Academias de Belém (PA), 1996.

\begin{tabular}{|c|c|c|c|c|c|}
\hline & Sexo & \multicolumn{2}{|c|}{ Masculino } & \multicolumn{2}{|c|}{ Feminino } \\
\hline \multicolumn{2}{|c|}{ Faixa etária (anos) } & $\mathrm{n}$. & $\%$ & $\mathrm{n}$. & $\%$ \\
\hline $11 \longmapsto$ & 19 & 5 & 15 & 7 & 10 \\
\hline 191 & 27 & 20 & 61 & 21 & 30 \\
\hline $27 \longmapsto$ & 35 & 4 & 12 & 22 & 31 \\
\hline $35 \mid-$ & 3 & 4 & 12 & 13 & 19 \\
\hline $43 \longmapsto$ & 51 & 0 & 0 & 6 & 9 \\
\hline $51 \longmapsto$ & & 0 & 0 & 1 & 1 \\
\hline Total & & 33 & 100 & 70 & 100 \\
\hline
\end{tabular}

Na Tabela 3, observa-se que ambos os sexos possuem o mesmo tempo de permanência nas academias, o que compreende entre 1 e 10 anos de prática. Quanto a carga horária diária e freqüência semanal, $38 \%$ praticam atividades com duração de 60 a 90 minutos de 3 a 5 vezes por semana, $42 \%$ praticam atividade com duração de 90 a 150 minutos de 3 a 5 vezes por semana e 20\% praticam atividade com duração de 150 a 210 minutos de 4 a 5 vezes por semana.

Do total de entrevistados que afirmaram utilizar suplementos nutricionais, $43 \%$ utilizam produtos a base de proteínas e aminoácidos, sendo que $23 \%$ usam exclusivamente estes (Tabela 4).
Tabela 3. Utilização de suplementos e tempo de prática esportiva, segundo o sexo. Academias de Belém (PA), 1996.

\begin{tabular}{llllll}
\hline & Sexo & \multicolumn{2}{c}{ Masculino } & \multicolumn{2}{c}{ Feminino } \\
\cline { 3 - 6 } prática (anos) & & n. & $\%$ & n. & $\%$ \\
\hline$<$ & 1 & 13 & 39 & 20 & 29 \\
$1 \longmapsto$ & 10 & 15 & 45 & 40 & 57 \\
$10 \longmapsto$ & 20 & 4 & 12 & 7 & 10 \\
$20 \longmapsto$ & 30 & 1 & 3 & 2 & 3 \\
$30 \longmapsto$ & 0 & 0 & 1 & 1 \\
\hline Total & & 33 & 100 & 70 & 100 \\
\hline
\end{tabular}

Tabela 4. Tipo de suplementos utilizados. Academias de Belém (PA), 1996.

\begin{tabular}{lll}
\hline \multirow{2}{*}{ Suplementos nutricionais } & Frequiencia \\
\cline { 2 - 3 } & $\mathrm{n}$. & $\%$ \\
\hline Proteínas e aminoácidos & 24 & 23 \\
Vitaminas e minerais & 54 & 53 \\
Associados* & 21 & 20 \\
Outros** & 4 & 4 \\
\hline Total & 103 & 100 \\
\hline
\end{tabular}

* Associação de proteínas e aminoácidos com vitaminas e minerais.

** Produtos à base de fibras e estimulantes energéticos.

Entre estes produtos destacam-se com maior frequiência: Massa 2000, Sustagem e Natubolic. O perfil de consumo específico por faixa etária e sexo, apresenta-se similar a distribuição global.

Em relação aos praticantes de atividade física que afirmaram utilizar algum tipo de suplemento nutricional, a maioria (54\%) relatou que o faz sem nenhuma indicação profissional, ou seja, por motivos diversos, tais como, a influência de amigos e parentes, propaganda ou iniciativa própria. $\mathrm{O}$ 
restante (46\%) afirmou manter acompanhamento com profissionais, entretanto esse resultado comparado ao levantamento de profissionais atuantes nas academias, indica que os mesmos são basicamente representados por professores de Educação Física, já que outros profissionais como médicos e nutricionistas só foram encontrados em quatro academias (Tabela 5).

Tabela 5. Motivos que levaram os praticantes de atividade física a utilizar algum tipo de suplemento nutricional. Academias de Belém (PA), 1996.

\begin{tabular}{lcc}
\hline \multirow{2}{*}{ Motivos } & \multicolumn{2}{c}{ Frequiência } \\
\cline { 2 - 3 } & $\mathrm{n}$. & $\%$ \\
\hline Influência de amigos e parentes & 23 & 22 \\
Propaganda & 1 & 1 \\
Iniciativa própria & 32 & 31 \\
Orientação profissional & 47 & 46 \\
\hline Total & 103 & 100 \\
\hline
\end{tabular}

Observou-se que a musculação é a atividade mais fortemente vinculada ao uso de repositores proteínicos tanto para homens $(100 \%)$ como para

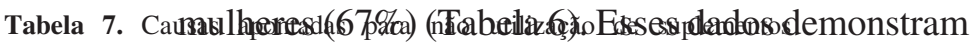

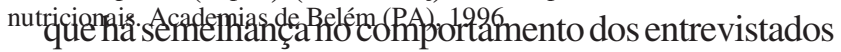
quanto ao uso de suplementiros quando comparados a estudos feitos na populaçãa alustraliana e norte-americana (Burke \& Read, 1993: Cardö'so, 1994).

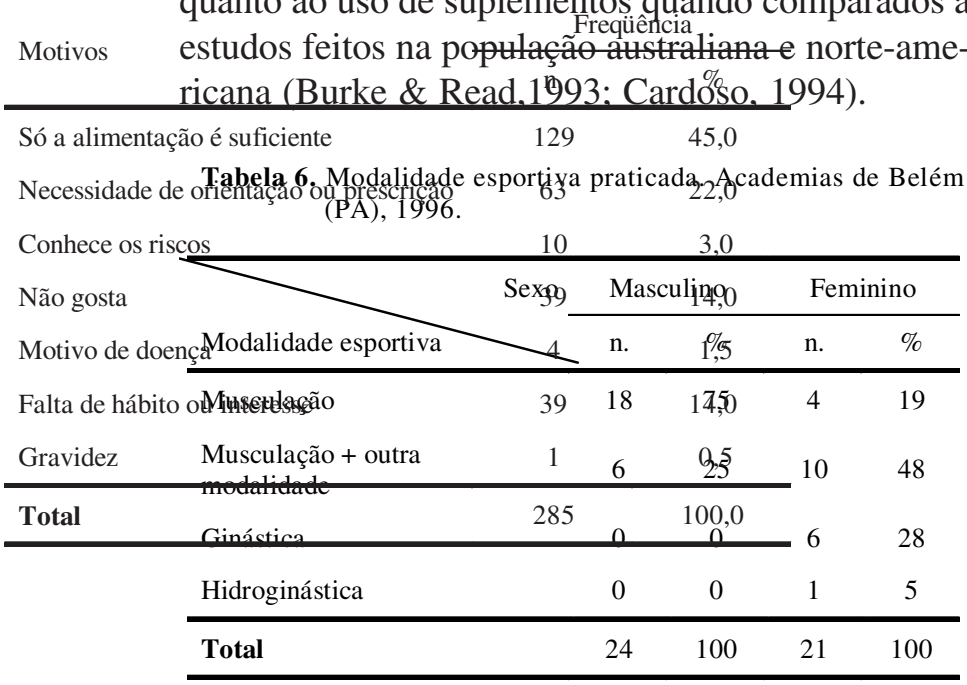

A maioria dos entrevistados que não fazem uso de suplementos nutricionais (73\%), demonstra ter alguma noção sobre a importância da alimentação como fonte exclusiva de nutrientes para as atividades físicas e que o uso de suplementos necessita de orientação profissional por apresentar risco a saúde. (Tabela 7).

\section{CONCLUSÃO}

De acordo com a literatura, concluiu-se que desde que, o esportista mantendo seu balanço energético (ingestão energética suficiente e adequada) e ingirindo em torno de $15 \%$ da energia provenientes de proteínas de alto valor biológico, a utilização de repositores proteínicos adicionais não é recomendável, uma vez que a maioria das pesquisas ratifica a necessidade de estudos mais longos e aprofundados sobre os reais benefícios advindos desse tipo de suplementação (Lemon,1991; Organización..., 1991).

Quanto aos resultados obtidos na pesquisa de campo, é possível formular algumas conclusões:

-Em princípio, o grupo estudado provavelmente não tem necessidade de utilização de repositores proteínicos, desde que mantenha um esquema alimentar adequado a sua idade, características físicas, tipo de atividade e outros fatores que interfiram em seu metabolismo orgânico;

- À exceção do quadro geral, foi detectada a presença de pessoas que em decorrência do longo período de prática de atividades físicas durante o dia (3 horas ou mais) poderão necessitar de suplementos, para fazer face a mobilização de reservas orgânicas que ocorre em situações de jejum e atividade física extenuante, o que, entretanto, só será evidenciado mediante avaliação nutricional e bioquímica apropriada; 
- A utilização de suplementação, nas academias pesquisadas, decorre basicamente da indicação feita por pessoas não habilitadas, ou por iniciativa do próprio usuário, ou seja, sem respaldo técnico para conduta;

- A maioria das academias não conta com o profissional nutricionista em seu quadro técnico para orientar aos usuários quanto à conduta alimentar de acordo com especificidades individuais, uma vez que este é o profissional técnico e legalmente habilitado para coordenar e executar atividades nesta área conforme determina a Lei n. 8.234/913;

- Detectou-se in loco a necessidade de atuação permanente de nutricionista como parte integrante da equipe multiprofissional para o atendimento individual/grupal, de ações educativas e de acompanhamento antropométrico, para resgatar a relevante importância dos aspectos alimentar e nutricional na promoção e manutenção da saúde geral das pessoas praticantes de atividade física regular,

- Todo e qualquer produto utilizado como suplemento nutricional deverá ser rigorosamente analisado por profissionais habilitados sobre os pontos de vista técnico e de adequação à legislação sanitária vigente no país.

\section{REFERÊNCIAS BIBLIOGRÁFICAS}

BURKE, L.M., READ, R.S.D. Dietary Supplements in Sport. Sport Medicine, Auckland,.15, n.1,p.43-65, 1993

BOWERS, R.W., FOX, E.L. Fisiologia del deporte. 3.ed. Buenos Aires : Médica Panamericana, 1995. p.13-34, 53-67.

CARDOSO, M.A. Suplementação dietética nos esportes. Nutrição Enteral e Esportiva. Rio de Janeiro, n.4, p.4-8, agosto, 1994.
FERNANDES, K., VIEIRA, M.L.B. Aminoácidos: estruturas fundamentais ao organismo. Nutrição Enteral e Esportiva, Rio de Janeiro, v.3, p.13-15, abril, 1994.

FOX, E.L., BOWERS, R.W., FOSS, M.L. Basesfisiológicas da educação física e dos desportos. 4.ed. Rio de Janeiro: Guanabara, 1991.p.10-26,374-388.

KATCH, F.I., MCARDLE, W.D. Nutrição, controle de peso e exercício. 2.ed. Rio de Janeiro : Medsi, 1984. p.35-47.

KREIDER, R.B., MIRIEL, V., BERTUN, E. Amino acid suplementation an exercise performance. Sport Medicine, v.16, n.3, Auckland, p.190-209, 1993.

KRAUSE, M.V. MAHAN, L.K. Alimentos, nutrição e dietoterapia. 7.ed. Rio de Janeiro : Roca, 1991. p.515-519.

LEMON,P.W.R. Effect of exercise on protein requeriments. Journal of Sports Sciences, London, v.9, n.1, p.53-70, 1991.

NEWSHOLME, E.A., BLOMSTRAND, E., EKBLOM, B. Physical and mental fatique: metabolic mechanisms and importance of plasma amino acids. British Medical Bulletin, London, v.48,n.3, p.477-495, 1992.

ORGANIZACIÓN PANAMERICANA DE LA SALUD. Instituto Internacional de Ciencias de la Vida. Conocimentos actuales sobre nutrición. 6.ed. Washington DC, 1991.p.394-396.

RODRIGUES, Y.T., GIOIA, O., EVANGELISTA, J. Adolescente, esporte e nutrição. São Paulo : Atheneu, 1984.p.29

WERUSTKY, C.A. Inibição da degradação protéica muscular (DPM) em atletas para suplementação de aminoácidos. Nutrição Enteral e Esportiva, Rio de Janeiro, v.6, p.4-7, maio, 1993.

Recebido para publicação em 15 de dezembro de 1997 e aceito em 15 de julho de 1998. 


\section{ANEXOS}

\section{ANEXO 1 \\ UNIVERSIDADE FEDERAL DO PARÁ CENTRO DE CIÊNCIAS DA SAÚDE DEPARTAMENTO DE NUTRIÇÃO}

Ficha de identificação da academia

1. Nome da academia:

2. Endereço:

3. 3. Horário de funcionamento:

4. 4. Número total de matriculados na academia:

5. 5. Profissionais atuantes na academia:

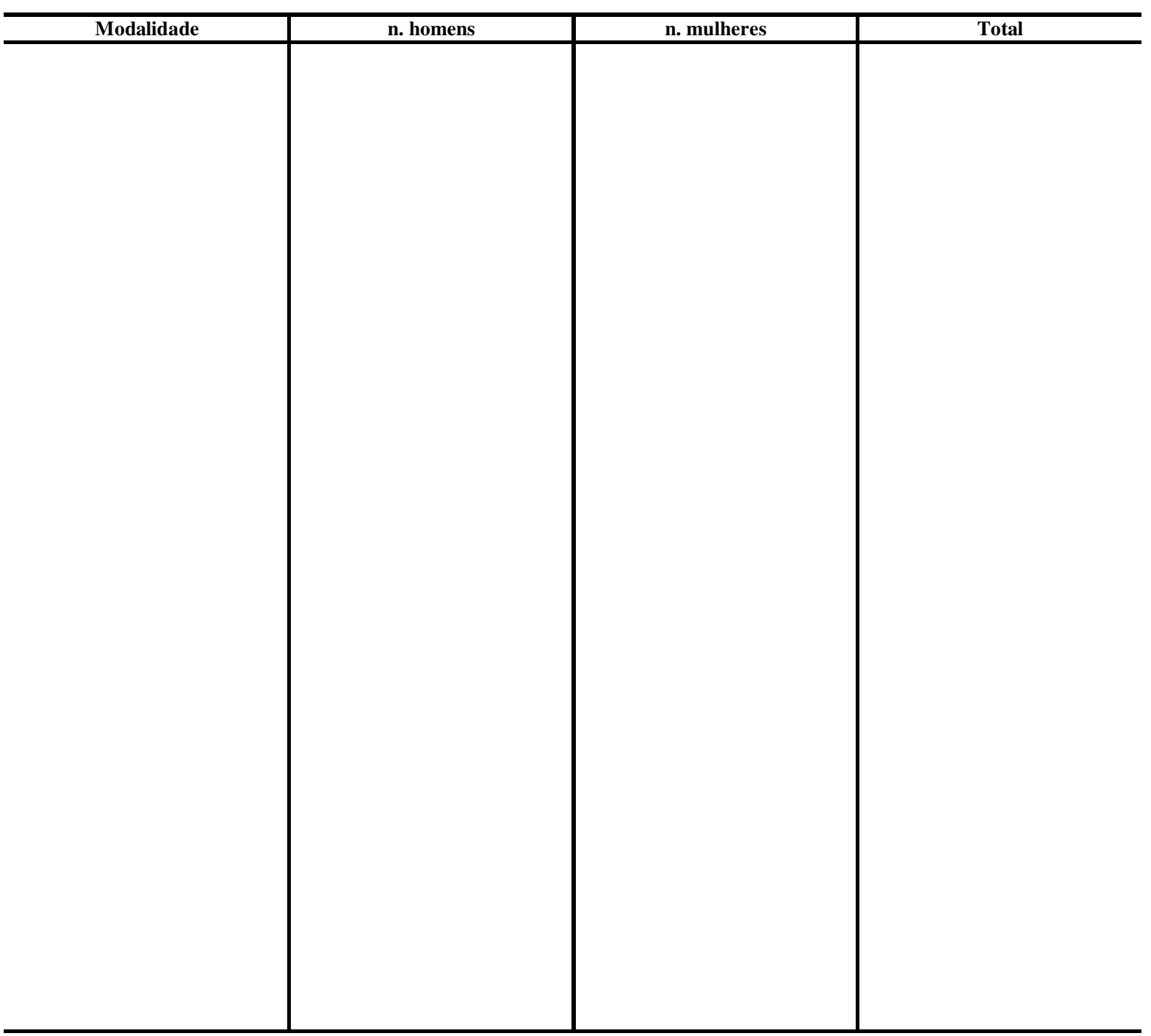


ANEXO 2

Academia:

N.:

\section{FORMULÁRIO}

1. Sexo Peso atual Altura $\quad$ Idade

$\mathrm{M} \square \mathrm{F} \square \quad \square \quad \mathrm{kg} \square \quad \mathrm{m} \square$ anos

2. Qual(is) são as sua(s) atividade(s) esportiva(s)?

$\mathrm{R}:$

3. Há quanto tempo pratica esta(s) atividade(s)?

$\mathrm{R}$ :

4. Qual a duração por dia? (horas)

$\mathrm{R}:$

5. Qual a freqüência na semana?

$\mathrm{R}$.

6. Usa algum tipo de suplemento?
( ) $\operatorname{Sim}$ ( ) Não
Por que?

7. Qual a base da fórmula do produto?
( ) Vitaminas
( ) Minerais
( ) Aminoácidos
( ) Outros

\section{Especifique:-}

Especifique:

Especifique:

\section{Especifique:}

8. Qual o nome do(s) produto(s)?

$\mathrm{R}:$

9. Qual a dosagem? Com que freqüência? Quanto tempo usa o produto?

$\mathrm{R}$ :

10. O que o levou a usar o produto?
( ) Influência de amigos
( ) Orientação profissional (médico, nutricionista,...)
( ) Propagandas (rádio, televisão, ...)
( ) Outros
( ) Iniciativa própria

11. Quais os resultados que você verifica com o uso do(s) produto(s)

$\mathrm{R}:$

12. Faz controle do uso do produto, com orientação profissional?

$\mathrm{R}$ : 


\section{ANEXO 3}

\section{RELAÇÃO DE TODOS OS REPOSITORES PROTEÍNICOS, COM RESPECTIVAS FREQÜÊNCIAS DE UTILIZAÇÃO.}

\begin{tabular}{lc}
\hline Produtos (nome comercial) & Freqüência \\
\hline Amino 2000 & 1 \\
Bcaa & 2 \\
Herbalife & 4 \\
L. Carnitina & 1 \\
Massa 600 & 2 \\
Massa 1200 & 7 \\
Massa 2000 & 2 \\
Massa 2500 & 3 \\
Massa 3000 & 3 \\
Mega mass & 5 \\
Natubolic & 1 \\
Nutrilite & 1 \\
Positrin & 7 \\
Sustagem & $\mathbf{4 0}$ \\
\hline Total & \\
\hline
\end{tabular}

Fonte: Pesquisa de Campo 